\title{
Pyrosequencing/Sanger Plant Genome Assembly (Limitations, Problems And Solutions) - On The Way To Cucumber (Cucumis sativus L. cv. Borszczagowski) Draft Genome Sequence Publishing
}

\author{
Rafal Woycicki ${ }^{\star}$, Zbigniew Przybecki \\ Dept. of Plant Genetics, Breeding \& Biotechnology, Faculty of Horticulture and Landscape Architecture, \\ Warsaw University of Life Sciences - SGGW, Nowoursynowska 159, 02-776 Warsaw, Poland
}

\section{Motivation.}

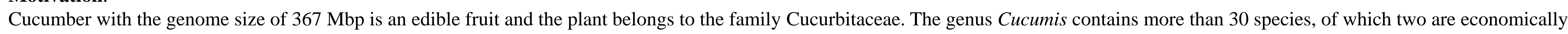

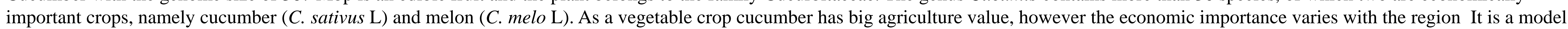
plant in studying sex determination and a lot of molecular marker maps with the help of BAC libraries and STCs should work fine to achieve this aim by positional cloning (1).

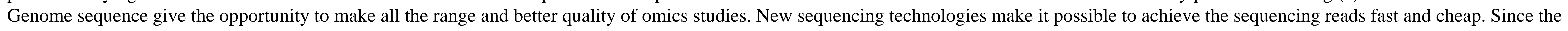
assembly step of such next generation reads is still not well standardized it is the most cumbersome part of sequencing projects.

Methods.

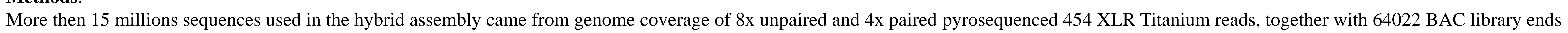

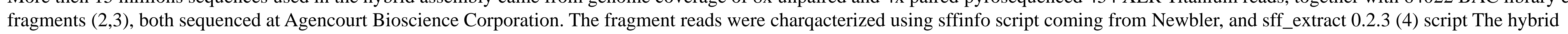

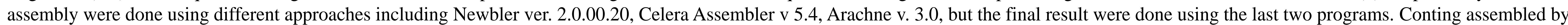

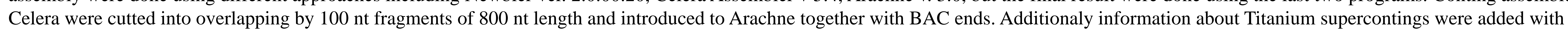
artificially prepaired paired ends (foreword and reverse). The assembly were done on 64bit workstation with 8 SSP and 32 GB RAM and took maxiumum 36h.

Table 2. Summary of assembly steps.

\begin{tabular}{|c|c|c|c|c|c|c|c|c|c|}
\hline Program used & Newbler & $\begin{array}{r}\text { Newbler }+ \\
\text { Arachne }\end{array}$ & Celera & Celera & Newbler & $\begin{array}{r}\text { Newbler }+ \\
\text { Arachne }\end{array}$ & Celera & Celera & $\begin{array}{l}\text { Celera }+ \\
\text { Arachne }\end{array}$ \\
\hline Reads type & $\begin{array}{r}8 x \text { UN } \\
\text { Titanium }\end{array}$ & $\begin{array}{r}8 \mathrm{x} \text { UN } \\
\text { Titanium } \\
+\mathrm{BAC} \\
\text { ends }\end{array}$ & $\begin{array}{r}8 \mathrm{x} \\
\text { Titanium }\end{array}$ & $\begin{array}{r}8 \mathrm{x} \mathrm{UN} \\
\text { Titanium } \\
+ \text { BAC } \\
\text { ends }\end{array}$ & \begin{tabular}{|r|}
$8 \mathrm{x} \mathrm{UN}+4 \mathrm{x}$ \\
$\mathrm{PA}$ \\
Titanium
\end{tabular} & $\begin{array}{r}8 \mathrm{x} \mathrm{UN}, 4 \mathrm{x} \\
\mathrm{PA}+\mathrm{BAC} \\
\mathrm{ends}\end{array}$ & $\begin{array}{r}8 \mathrm{x} \mathrm{UN}+4 \mathrm{x} \\
\mathrm{PA} \\
\text { Titanium }\end{array}$ & $\begin{array}{r}8 \mathrm{x} \text { UN, } 4 \mathrm{x} \\
\mathrm{PA}+\mathrm{BAC} \\
\text { ends }\end{array}$ & $\begin{array}{r}8 \mathrm{x} U N, 4 \mathrm{x} \\
\mathrm{PA}+\mathrm{BAC} \\
\text { ends }\end{array}$ \\
\hline $\begin{array}{r}\text { Titanium reads } \\
\text { used }\end{array}$ & 7423671 & NA & 6418446 & 6418446 & 13404638 & NA & 11125634 & 11125634 & NA \\
\hline $\begin{array}{l}\text { BAC ends } \\
\text { reads used }\end{array}$ & NA & 62750 & NA & 62750 & NA & 62750 & NA & 62750 & 64022 \\
\hline $\begin{array}{r}\text { Fake reads } \\
\text { used }\end{array}$ & NA & 215663 & NA & NA & NA & 176305 & NA & NA & 285037 \\
\hline $\begin{array}{r}\text { Fake mate } \\
\text { paired read } \\
\text { used }\end{array}$ & NA & NA & NA & NA & NA & NA & NA & NA & 82496 \\
\hline No. Contigs & 57783 & 40294 & 35613 & 34753 & 225309 & 46487 & 15514 & 15667 & 16403 \\
\hline $\begin{array}{r}\text { Contigs length } \\
\text { sum (Mbp) }\end{array}$ & 190 & 177 & 183 & 189 & 192 & 110 & 196 & 197 & 193 \\
\hline $\begin{array}{r}\% \text { genome } \\
\text { size in contigs }\end{array}$ & $51.77 \%$ & $48.23 \%$ & $49.86 \%$ & $51.39 \%$ & $52.32 \%$ & $29.97 \%$ & $53.30 \%$ & $53.79 \%$ & $52.59 \%$ \\
\hline $\begin{array}{r}\text { No. Contigs } \\
>1000 \mathrm{nt}\end{array}$ & 31768 & 37102 & 35612 & 34753 & 62846 & 43055 & 15222 & 15196 & 15686 \\
\hline $\begin{array}{r}\text { Mean contig } \\
\text { length }\end{array}$ & 5656 & 4708 & 5155 & 5428 & 2107 & 2496 & 12839 & 12972 & 12264 \\
\hline $\begin{array}{r}\text { N50 contig } \\
\text { length }\end{array}$ & 8361 & 6206 & 7635 & 8281 & 2288 & 2601 & 24714 & 27086 & 23280 \\
\hline $\begin{array}{r}\text { No. } \\
\text { Supercontigs }\end{array}$ & NA & 39071 & NA & 33495 & 12087 & 46256 & 4976 & 4173 & 12944 \\
\hline $\begin{array}{r}\text { Supercontigs } \\
\text { span sum }\end{array}$ & NA & 278 & NA & 300 & 126 & 126 & 198 & 224 & 321 \\
\hline $\begin{array}{r}\% \text { genome } \\
\text { size in } \\
\text { supercontigs }\end{array}$ & NA & $75.61 \%$ & NA & $81.74 \%$ & $34.33 \%$ & $34.33 \%$ & $53.84 \%$ & $61.14 \%$ & $87.47 \%$ \\
\hline $\begin{array}{r}\text { No. } \\
\text { Supercontigs } \\
>1000 \mathrm{nt}\end{array}$ & NA & 35894 & NA & 33495 & 12087 & 42839 & 4967 & 4157 & 12310 \\
\hline $\begin{array}{r}\text { Mean } \\
\text { supercontig } \\
\text { span } \\
\end{array}$ & NA & 7664 & NA & 8948 & 10473 & 2873 & 39799 & 54070 & 26046 \\
\hline $\begin{array}{r}\mathrm{N} 50 \\
\text { supercontig } \\
\text { span }\end{array}$ & NA & 11992 & NA & 19122 & 16537 & 2853 & 158310 & 2324038 & 372416 \\
\hline
\end{tabular}

Results

Average length of 7'970'914 unpaired reads was $374 \mathrm{nt}$. Reads coming from sequencing of paired Titanium library consisted of 3'204'606 paired reads (containing linker) with the length of $171 \mathrm{nt}, 892328$ unpaired reads (multi or partial linker) with the length of $195 \mathrm{nt}$ and 3106927 unpaired reads (no linker) with the length of $227 \mathrm{nt}$. Lengths of pyrosequenced fragments are showed on Fig. 1 i 2 and Table 1. Average length of 64022 BAC end sequences was $737 \mathrm{nt}$. Summary of assembly results is shown in Table 2. Below you can find detailed information about finally chosen method. Titanium $8 \mathrm{x}$ unpaired \& 4x paired reads were assembled using Celera. From 11125634 (73.31\% of all reads) 8506533 were assembler into 15514 contigs of $195.6 \mathrm{Mbp}$ length with the average length of $12839 \mathrm{nt}$ and N50 of $24714 \mathrm{nt}$. Number of supercontigs was 4976 of coverage 197. 6. Average coverage of supercontigs was $39799 \mathrm{nt}$ and N50 was $158310 \mathrm{nt}$. Number of reads recognized to be repeated sequences and not uniqally assembled was 2338980 . From 2823642 paired Titainium reads recognized by Celera $(88.11 \%$ of recognized by sff_extract), 1610390 (57.03\%) were used in the assembly and only 1298323 (45.98\%) were assembled into contigs. Beside resulting contigs and supercontigs, Celera had made also 160714 degenerate contigs of the total length of $76.5 \mathrm{Mbp}$ which consisted of partially assembled repeated sequences which could not be uniqally assembled into contigs. The degenerate contigs were not used in the next step of hybrid assembly. Hybrid assembly were finished using Arachne assembler. The assembler used 285037 unpaired pseudo-reads generated from 15514 Celera contigs together with 64022 BAC ends and 82496 artificial paired reads containing information about Titanium Celera supercontigs. Number of generated contigs were 16547 of the length $193.2 \mathrm{Mbp}$, average length was $12214 \mathrm{nt}$ and N50 $23280 \mathrm{nt}$. Number of supercontigs were 13129 with the coverage of $323 \mathrm{Mbp}$. The average coverage of supercontigs was $25865.9 \mathrm{nt}$ and N50 was $323092 \mathrm{nt}$. Corectness of the assembly were propen after mapping 95,56\% of 63035 cucumber unigenes (5) with the homology higher then $95 \%$.

As shown in Table 2, assembly of Titanium and BAC end reads with Celera resulted in increasing of supercontigs coverage only by $27 \mathrm{Mbp}$ from $197 \mathrm{Mbp}$ to $224 \mathrm{Mbp}$ in compare to $323 \mathrm{Mbp}$ achieved by Arachne. This could be the result of the fact that on the sequencing contigs Celera mapped only 42774 of used BAC ends (66.54\%), the rest of them were in degenerate contigs. On the contrary number of BAC ends mapped on sequencing contigs by Arachne was $52524(82.04 \%)$.

\section{Summary}

The above results show that its now possibile to sequence and correctly denovo assembler practically every genome. Advanced draft assembly of highly repetitive plant genome were achieved after hybrid approach with the use of pyrosequencing 454 XLR Titanium 12x coverage paired and unpaired reads and BAC end sequences. The coverage used came to be optimall for such a genome.

Table 1. Titanium reads statistics

\begin{tabular}{|c|c|c|c|c|c|}
\hline & $\begin{array}{l}\text { 4x unpaired } \\
\text { partial/multi } \\
\text { linker }\end{array}$ & $\begin{array}{l}\text { 4x paired } \\
\text { full linker }\end{array}$ & $\begin{array}{l}\text { 4x unpaired } \\
\text { no linker }\end{array}$ & 8x UN & Summary \\
\hline $\begin{array}{l}\text { All reads } \\
\text { No. }\end{array}$ & 892328 & 3204606 & 3106927 & 7970914 & 15174775 \\
\hline$<100 \mathrm{nt}$ & $28.05 \%$ & $33.67 \%$ & $25.62 \%$ & $6.49 \%$ & \\
\hline $100-200 \mathrm{nt}$ & $26.89 \%$ & $28.46 \%$ & $25.03 \%$ & $9.45 \%$ & \\
\hline $200-300 \mathrm{nt}$ & $22.12 \%$ & $21.09 \%$ & $18.03 \%$ & $10.59 \%$ & \\
\hline $300-400 \mathrm{nt}$ & $16.90 \%$ & $13.01 \%$ & $14.32 \%$ & $18.80 \%$ & \\
\hline $400-500 \mathrm{nt}$ & $5.85 \%$ & $3.65 \%$ & $13.87 \%$ & $36.05 \%$ & \\
\hline$>500 \mathrm{nt}$ & $0.19 \%$ & $0.12 \%$ & $3.04 \%$ & $18.25 \%$ & \\
\hline Av. length & 195.45 & 171.53 & 227.07 & 374.00 & 290.66 \\
\hline Total length & 174409126 & 549690047 & $\mid \begin{array}{lll}705 & 481 & 264\end{array}$ & 2981159897 & $\begin{array}{r}4410740 \\
334\end{array}$ \\
\hline $\begin{array}{l}\text { Genome } \\
\text { coverage }\end{array}$ & 0.48 & 1.50 & 1.92 & 8.12 & 12.02 \\
\hline
\end{tabular}

Figure 1. Titanium reads lengths (with linker) $-\mathrm{UN} 8 \mathrm{x}-\mathrm{PA} 4 \mathrm{x}$

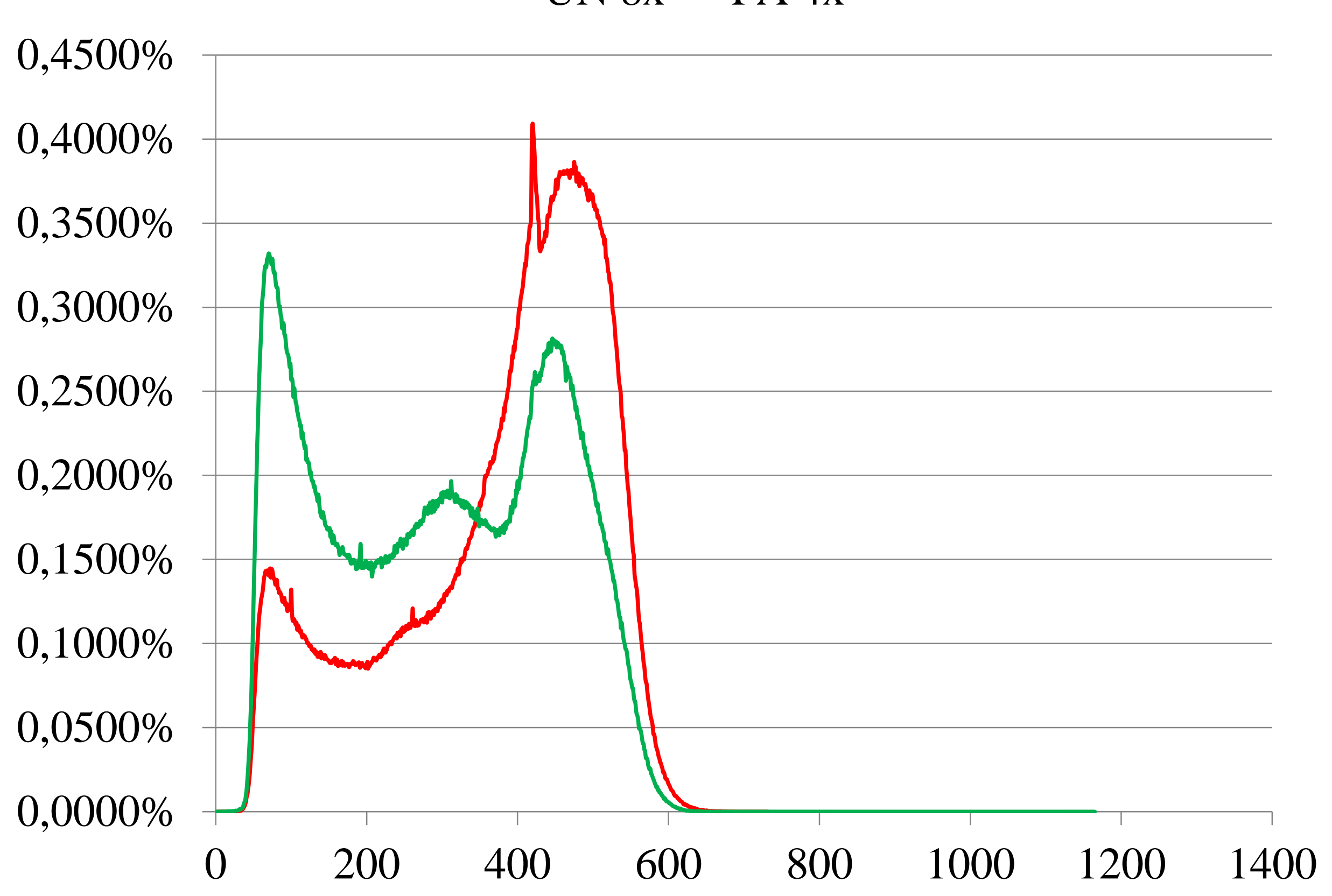

Figure 2. Titanium reads lengths after linker extraction $-4 \mathrm{x}$ unpaired partial/multi linker $-4 \mathrm{x}$ paired full linker $-4 \mathrm{x}$ unpaired no linker $-8 \mathrm{x}$ UN

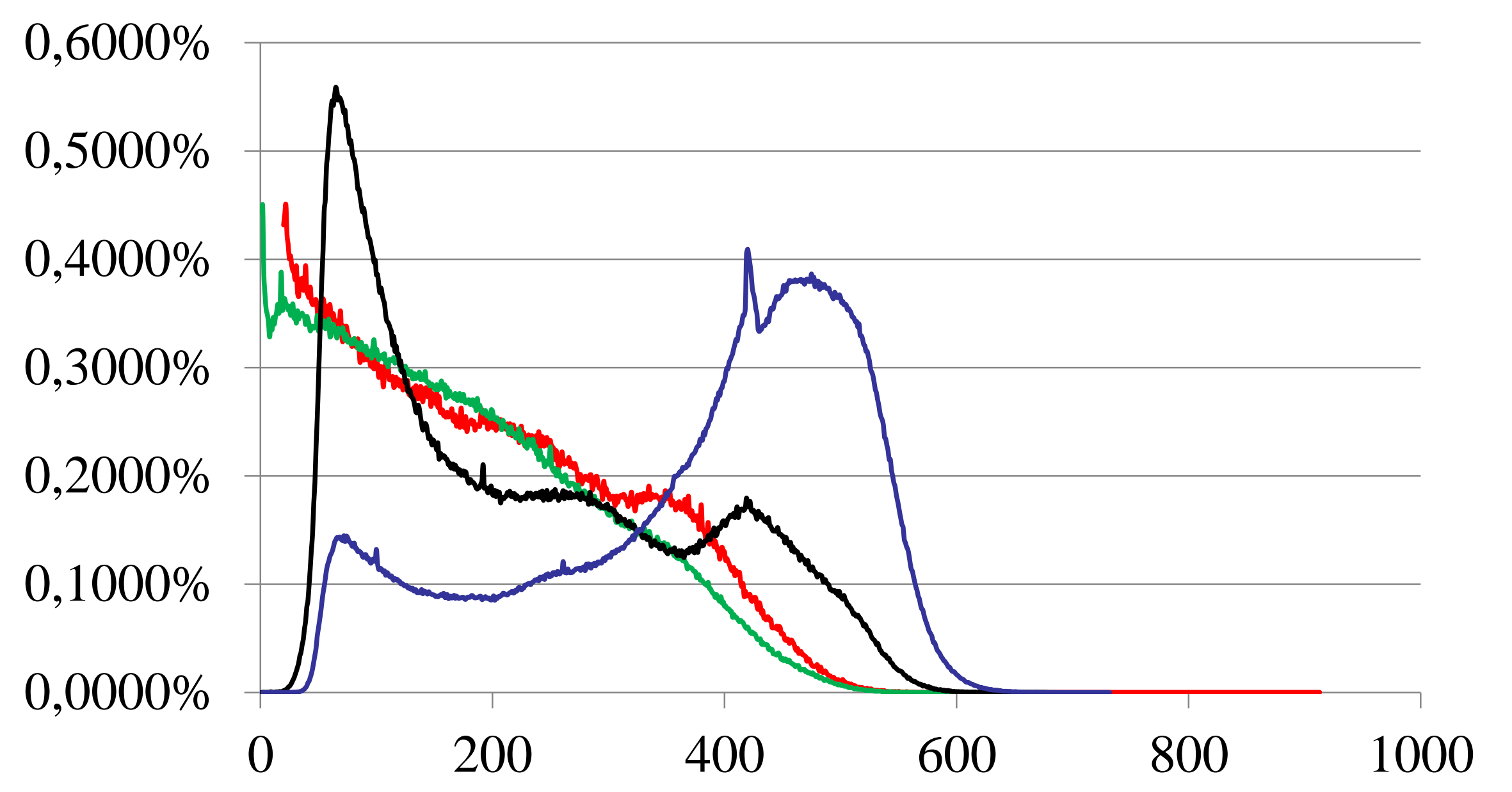

